\title{
Penetrating Ocular Trauma with Retained Intraocular Foreign Body: Management, Follow-up and Medico-legal Evaluation
}

S Sorrentino ${ }^{1}$, LT Marsella ${ }^{2}$, A Feola ${ }^{3}$, V Marino ${ }^{4}$, B Billi ${ }^{1,5}$

\begin{abstract}
Ocular trauma is the leading cause of acquired monocular blindness, accounting for 1.97-6\% of such cases. Particularly, penetrating ocular injuries are among the most common eye injuries with this kind of outcome. Early diagnosis and prompt management are crucial to avoid complications, and the especially dreaded enucleation. In this article, the authors describe the clinical management, and evaluate the visual and anatomical results obtained in a case of ocular injury with retained intraocular foreign body (IOFB) in a 20-year old female patient. The course of treatment involved a combination of penetrating keratoplasty with a temporary keratoprosthesis, phacoemulsification with intraocular lens implantation and pars plana vitrectomy. At three years from the initial injury, the patient was able to count fingers at 30 centimetres and anatomical restitutio ad integrum of the globe had been achieved.
\end{abstract}

Keywords: Intraocular foreign body, keratoprosthesis, vitrectomy

\section{Trauma ocular penetrante con retención de un cuerpo intraocular extraño: tatamien- to, seguimiento, y evaluación médico-legal \\ S Sorrentino ${ }^{1}$, LT Marsella ${ }^{2}$, A Feola ${ }^{3}$, V Marino ${ }^{4}$, B Billi1 ${ }^{1,5}$}

\begin{abstract}
RESUMEN
El trauma ocular es la causa principal de ceguera monocular adquirida, representando el 1.97 $6 \%$ de estos casos. En particular, las lesiones oculares penetrantes se hallan entre las lesiones más comunes del ojo con este tipo de resultado. El diagnóstico temprano y el tratamiento a tiempo son cruciales para evitar las complicaciones, especialmente la tan temida enucleación. En este artículo, los autores describen el manejo clínico y la evaluación de los resultados visuales y anatómicos obtenidos en el caso de una lesión ocular con cuerpo extraño intraocular retenido, en una paciente de 20 años. El curso del tratamiento comprendió una combinación de queratoplastia penetrante con una queratoprostesis temporal, facoemulsificación con implantación de lente intraocular, y vitrctomía de la pars plana. Tres años luego de la lesión inicial, el paciente era capaz de contar los dedos a 30 centímetros, y se había alcanzado la restitución integral anatómica del globo ocular.
\end{abstract}

Palabras claves: Cuerpo extraño intraocular, keratoprostesis, vitrectomía

West Indian Med J 2016; 65 (2): 391

\section{INTRODUCTION}

Ocular traumas are the leading cause of acquired unilateral blindness [1.97-6\% of all injuries] (1). The Birmingham Eye Trauma Terminology classification system divides such

From: 'Department of Ophthalmology, University of Rome "Campus Bio-Medico", Rome, Italy, ${ }^{2}$ Legal Medicine and Social Security Services, Department of Biomedicine and Prevention, University of Rome "Tor Vergata", Rome, Italy, ${ }^{3}$ Department of Experimental Medicine, Second University of Naples, Naples, Italy, ${ }^{4}$ Section of Legal Mediciine, University of Rome "Tor Vergata", Rome, Italy, traumas into open and closed globe injuries (1). The open globe injuries can be caused by laceration (penetrating trauma, injury with retention of a foreign body (IOFB or perforating trauma) or blunt trauma (2). Ten per cent of IOFBs result

and 5 "GB Bietti" Foundation for Study and Research in Ophthalmology, Rome, Italy.

Correspondence: Dr S Sorrentino, Policlinico Universitario Campus Bio-Medico, via Alvaro del Portillo 21,00128, Roma, Italy. E-mail: s.sorrentino@unicampus.it 
in total blindness, and of these, $4 \%$ are subjected to elective enucleation due to blindness and/or persistent pain (3).

\section{CASE REPORT}

A 20-year old woman was transported to our Trauma Centre, after a frontal car collision. A full-body computed tomography scan showed a fractured left clavicle, an anterior maxillary sinus fracture, a fracture of the orbit lateral wall with displaced fragments, haemosinus and a foreign body of $6 \mathrm{~mm}$ at the posterior pole of the left eye (a windscreen fragment). The initial ophthalmic examination of the left eye documented a $7 \mathrm{~mm}$ sclerocorneal laceration due to a sharp object, iris prolapse and the presence of an IOFB. Initially, the closure of the sclerocorneal wound and anterior chamber wash-out with vancomycin was done under general anaesthesia. One week later, the visual acuity of the left eye (LE VA) was counting fingers at one metre. Slit lamp examination showed a mild conjunctival hyperaemia, a $7 \mathrm{~mm}$ sclerocorneal suture, diffuse corneal oedema and traumatic cataract. The intraocular pressure (IOP) was $22 \mathrm{mmHg}$. Due to media opacities, the ocular fundus could not be thoroughly examined. A surgical procedure combining temporary keratoprosthesis, penetrating keratoplasty (PK), phacoemulsification with IOL implantation and pars plana vitrectomy (PPV) with IOFB removal and silicone oil endotamponade was then carried out (Figs. 1-3).

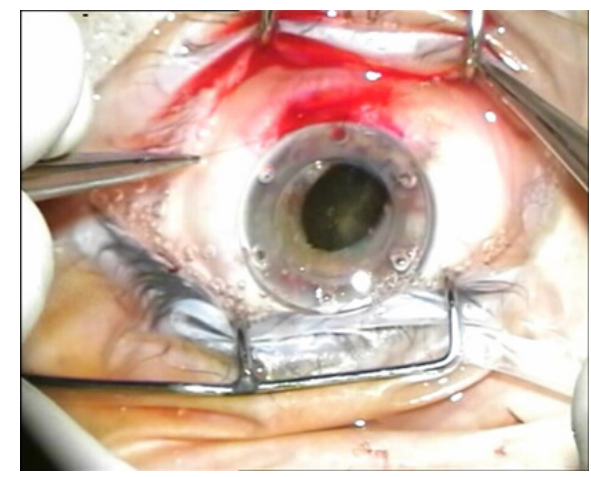

Fig. 1: The surgeon suturing the temporary keratoprosthesis.

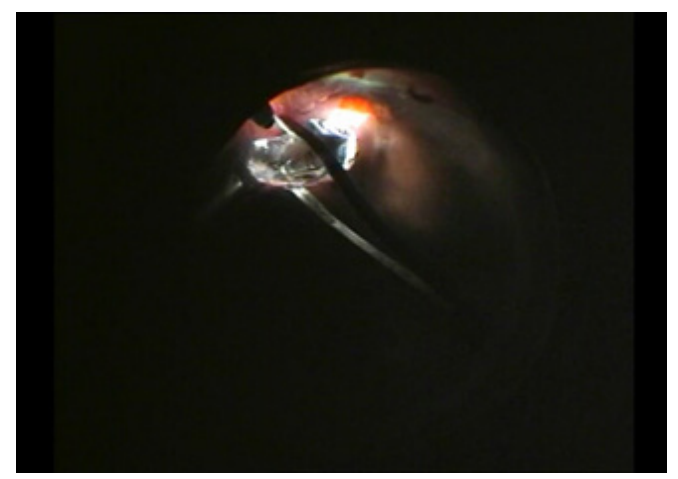

Fig.2: Removal of the intra-ocular foreign body (fragment of the car wind-screen) with vitrectomy forceps $23 \mathrm{G}$.

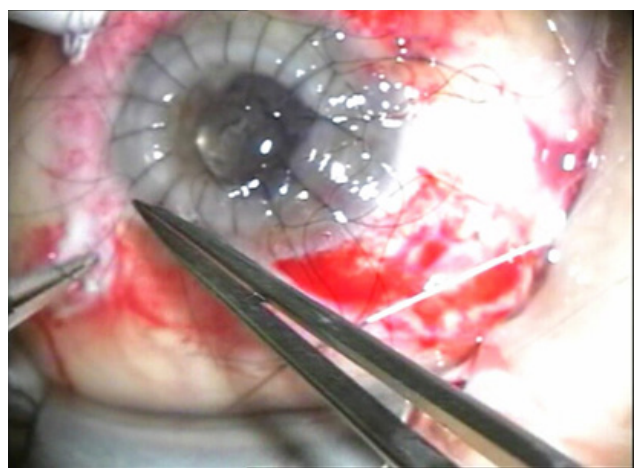

Fig. 3: Penetrating kerotoplasty.

The patient attended regular outpatient appointments, and maintained an LE VA of 0.2 and a normal IOP through this period. Five months later, she returned to our clinic with symptoms including lacrimation, photophobia, eye pain and decreased VA. A slit lamp examination showed subepithelial corneal oedema and an IOP of $32 \mathrm{mmHg}$. A rejection reaction was diagnosed, so systemic and topical corticosteroids combined with hypotonic eye drops were applied. A good clinical outcome was achieved through this therapeutic approach. One year later, the patient complained of a further decline in visual acuity and eye pain, despite continuing the hypotonic treatment at home (LE VA: counting fingers at $30 \mathrm{~cm}$; IOP 36 $\mathrm{mmHg}$ ). A refractory glaucoma was diagnosed and an Ahmed valve was implanted. Three months after the implantation of the valve, a further deterioration in visual acuity and an increase in the IOP was observed (LE VA: hand motion; IOP $27 \mathrm{mmHg}$ ). Slit lamp examination showed the presence of emulsified silicone oil in the anterior chamber, and the resulting occlusion of the Ahmed valve drainage tube. Following an anterior chamber wash-out, the LE VA was improved to counting fingers at $30 \mathrm{~cm}$ and IOP decreased to $13 \mathrm{mmHg}$. Ten months after the valve implantation, the patient was pregnant and displayed clinical signs of endothelial rejection. In agreement with the patient, a further procedure, involving PK and PPV with silicone oil exchange, was carried out using a temporary keratoprosthesis. At the last follow-up, three years after the initial trauma, the patient's LE VA was counting fingers at $30 \mathrm{~cm}$ while the IOP was $18 \mathrm{mmHg}$. The clinical examination showed satisfactory corneal transparency and PK results, optically empty anterior chamber, and the correctly positioned IOL. Fundus examination showed a successful outcome of the PPV, IOFB removal and laser treatment, together with a $360^{\circ}$ retina adhesion.

\section{DISCUSSION}

An IOFB can be removed during the initial surgery. The method of choice under normal circumstances is PPV, but in most cases, severely injured eyes require further surgical procedures. As in our case, an opaque lens can be removed with a procedure combining a PK and a PPV, and, depending on the anatomical conditions, an IOL can be implanted. The decision 
to implant the IOL in the present case was made due to the refractive benefits of this approach in the postoperative period, including prevention of the onset of a secondary glaucoma in an aphakic eye treated with silicone oil. The use of silicone oil as a tamponade is dictated by the high risk of developing a traction retinal detachment due to proliferative vitreo-retinopathy (4). Risk factors for the development of PVR are vitreous haemorrhage, retinal detachment and dispersion of retinal pigment epithelial cells. The retinal pigment epithelial cells, with inflammatory mediators, arising from a post-traumatic rupture of the blood-retinal barrier, act as a stimulus for cell proliferation and intraocular scarring (4). The use of silicone oil provides protection against atrophy and elective enucleation.

The probability of developing corneal rejection is greater in cases of traumatic injury. Corneal rejection can be: Epithelial: $(10 \%)$ the immune response is directed toward the epithelium of the donor. The lymphocytes form a linear "bridge" with a raised centripetal spread, which stains with both fluorescein and rose bengal. Subepithelial: characterized by the presence of infiltrates measuring $0.2-0.5 \mathrm{~mm}$ below Bowman's membrane. A slight increased cellularity is often observed in the anterior chamber. Stromal: has a sudden onset, characterized by a thick haze, and is associated with a perikeratic reaction. Endothelial: a perikeratic reaction is observed, with oedema and keratic precipitates that can be scattered or form an irregular line (Khodadoust line). In the latter case, the precipitates originate from the peripheral cornea with neovascular or synechiae formations. The precipitates are deposited centrally over the endothelium, causing endothelial decompensation. A moderate to severe reaction in the anterior chamber is always present.

A serious complication associated with penetrating keratoplasty and the use of silicone oil is the development of a secondary glaucoma. Secondary glaucoma following a PK is a significant cause of graft failure and blindness. Its pathophysiology is multifactorial, and may be related to an angular distortion with the collapse of the trabecular meshwork, suture technique, postoperative inflammation, use of corticosteroids and the formation of peripheral anterior synechiae. The late formation of synechiae has been shown to be the most common cause of secondary glaucoma that occur in a 3-40\% of patients who have undergone vitreoretinal surgery with silicone (5). The incidence ranges from $2.2-56 \%$ at six to eight months (5). The mechanisms resulting in a secondary glaucoma can be summarized in seven causes: pupillary block, silicone oil migration, clogging of the trabecular meshwork by oil droplets, inflammation and trabeculitis, synechiae, overfilling the vitreous cavity with silicone oil, and pre-existing angle pathology/glaucoma. In $30 \%$ of cases, topical and systemic drugs are required, and $50 \%$ of patients need long-term treatment. Surgical removal of silicone oil alone does not lead to a reduction of IOP; in $25 \%$ of cases, topical therapy is needed. Because of the risk of developing refractory glaucoma, a surgical approach must be considered. Drainage devices can be used as an alternative to trabeculectomy and panretinal photo- coagulation. Such devices create an alternative course for the aqueous humor outflow from the anterior chamber through a tube with an equatorial plate that encourages bleb formation. Currently, available drainage devices include valved devices that create a resistance to the aqueous flow, such as the Ahmed or the Krupin valves, and non-valved devices, which do not restrict the flow, such as the Molteno and the Baerveldt valves. The risk of developing postoperative hypotony is greater with the non-valved devices. In the present case, we chose to use a FP7 Ahmed valve (flexible plate), which is generally considered to be a good solution in patients with secondary glaucoma following a vitreoretinal surgery. Because of the valve mechanism, IOP does not decrease sharply and the risk of re-detachment is thus reduced. Patients with refractory glaucoma who suffer recurrent episodes of ocular hypertension and display a consistently high IOP usually develop irreversible endothelial decompensation with bullous keratopathy (6). For this reason, drainage device implantation plays a crucial role in IOP management in such patients. Unfortunately, the risk of corneal rejection may increase as a result of drainage system implantation. This happens because the drainage tube can become a conduit for the passage of inflammatory cells to the anterior chamber. In the present case, the corneal rejection was most likely multifactorial. Moreover, the presence of silicone oil played an important role in accelerating the process of corneal decompensation due to the damage to the graft caused by the endothelium-oil contact and the increased IOP. It has been shown that $60 \%$ of corneal transplant patients develop decreased endothelial cell counts two years after drainage device implantation, especially in cases with a shallow anterior chamber that allows contact between the iris and the drainage tube (6). In cases where a combined surgery for both retinal and corneal defects is required, temporary keratoprostheses allow good visualization of intraocular structures, prevent damage to the donor graft during surgical manoeuvres, and help to maintain an adequate IOP (7). Once the vitrectomy is carried out, the temporary keratoprosthesis can be removed and replaced with a transparent graft. In an open globe injury with a retained intraocular foreign body, the level of visual acuity is not predictable due to the extent of the damage that is usually difficult to assess, and the complexity of the surgical treatment.

\section{CONCLUSIONS}

As in our case, ocular trauma is very frequent during road accidents $(8,9)$. Our patient was subjected to various surgical procedures, and although the functional outcome is not optimal, the anatomical integrity of the affected eye is preserved with some satisfaction. Given the young age of the patient, this achievement is of significant aesthetic and psychological importance. From a medico-legal point of view, the assessment of injuries involving retained intraocular foreign bodies can be based on two prevailing prospects: the functional and the aesthetic outcome. In terms of the former, in the present case, the consequences were extremely significant, with a se- 
verely compromised visual acuity in the left eye (counting fingers at $30 \mathrm{~cm}$ ), while from the aesthetic point of view, an appropriate ophthalmic management enabled the preservation of the anatomical integrity of the affected eye.

\section{REFERENCES}

1. Schmidt GW, Broman AT, Hindman HB, Grant MP. Vision survival after open globe injury predicted by classification and regression tree analysis Ophthalmology 2008; 115: 202-9.

2. Kuhn F, Morris R, Witherspoon CD, Heimann K, Jeffers JB, Treister G. A standardized classification of ocular trauma. Ophthalmology 1996; 103: $240-3$.

3. Choovuthayakorn J, Hansapinyo L, Ittipunkul N, Patikulsila D, Kunavisarut P. Predictive factors and outcomes of posterior segment intraocular foreign bodies. Eye (Lond) 2011; 12: 1622-6.

4. Szurman P, Roters S, Grisanti S, Aisenbrey S, Rohrbach JM, Warga M.
Primary silicone oil tamponade in the management of severe intraocular foreign body injuries: an 8-year follow-up. Retina 2007; 27: 304-11.

5. Romano MR, Angi M, Romano V, Parmeggiani F, Campa C, Valldeperas $\mathrm{X}$. Intraocular pressure changes following the use of silicone oil or Densiron ${ }^{\circ} 68$ as endotamponade in pars plana vitrectomy. Clin Ophthalmol 2010; 4: 1391-6.

6. Bates AK, Hiorns RW, Cheng H. Modeling of changes in the corneal endothelium after cataract surgery and penetrating keratoplasty. Br J Ophthalmol 1992; 76: 32-5.

7. Garcia-Valenzuela E, Blair NP, Shapiro MJ, Gieser JP, Resnick KI, Solomon MJ et al. Outcome of vitreoretinal surgery and penetrating keratoplasty using temporary keratoprosthesis Retina 1999; 19: 424-9.

8. Mowatt L, McDonald A, Ferron-Boothe D. Hospitalization trends in adult ocular trauma at the University Hospital of the West Indies. West Indian Med J 2012; 61: 605-9.

9. Feola A, Marino V, Sorrentino S, Marsella LT. Medico-legal and traumatological aspects of orbital fractures: a case report. EuroMediterr Biomed J 2013; 8: 140-5. 